\title{
Impact of Global Oil Shocks on the Russian Stock Market
}

\author{
Igor Lukasevich ${ }^{1},{ }^{*}$, and Ludmila Chikileva ${ }^{2}$ \\ ${ }^{1}$ Financial University under the Government of Russian Federation, Department of Corporate Finance \\ and Corporate Management, Moscow, Russia \\ ${ }^{2}$ Financial University under the Government of Russian Federation, Department of the English \\ Language and Professional Communication, Moscow, Russia
}

\begin{abstract}
.
Research background: The study focuses on modeling assessment of oil shocks impact on the Russian stock market.

Purpose of the article: The purpose of the study is to determine the impact of oil prices abrupt changes on the Russian stock market, its quantitative and temporal specifications. The study consists of two interrelated sections. The first section includes the results of statistical processing of initial data, calculation of their key characteristics and preliminary analysis. The second section of the study is devoted to modeling the assessment of the impact of oil shocks on the behavior of the Russian market RTS stock index.

Methods: Based on an extensive sample of daily price values for Brent North sea oil and the Russian stock index RTS for the period from 1997 to May 2020, the study was conducted using models vector auto regression (VAR-model).

Findings \&Value added: The VAR model was developed and tested to assess the impact of oil shocks on the Russian stock market. Unlike the results of other studies, it is shown that the Brent oil price variance explains only about $10 \%$ of the RTS index yield variance in long-term time intervals. The low correlation of time series data and time limit of the impact of oil shocks on the Russian market have been revealed. According to the results of the study, the market recovery takes about 2 months, then the stock index returns to the 'historical' range of average \pm standard deviation.
\end{abstract}

Keywords: oil shocks; stock market; econometric methods; modeling; vector auto regression models (VAR)

JEL Classification: $C 01$; $C 32$; $G 14 ; G 17$

*Corresponding author: lukas1963@yandex.ru 


\section{Introduction}

The first half of 2020 was marked by the implementation of an unprecedented combination of two independent global events - the coronavirus pandemic and a sharp drop in oil prices. Despite the different nature, the origins and the reasons for implementation, they had a catastrophic shock effect both on the world economy as a whole and on the local markets of individual countries.

Stock markets are usually the first to react to such changes, so they are like barometers demonstrating the state of the economy. The markets experienced the largest daily fall on March 9, 2020, which has already gone down in history as "Black Monday". The drop in oil prices by $22 \%$ led to a sharp decline in stock indices (Table 1 ) nearly in all the countries.

Table 1. Drop of major stock indices on March 9, 2020

\begin{tabular}{|c|c|c|c|c|c|c|}
\hline Index & S\&P500 & FTSE100 & S\&P/TSX & IBOVESPA & CAC40 & DAX \\
\hline Day drop (\%) & 7,6 & 7,7 & 10 & 12 & 8,4 & 7.9 \\
\hline
\end{tabular}

The Russian stock index of Moscow Exchange, calculated in roubles, under the influence of a combination of both factors, lost more than 30\% in March from the maximum since the beginning of the year, and the RTS index, determined in US dollars, more than $41 \%$.

The unpredictability of the timing and scale of the consequences of such events brings to the fore the task of analysing and modelling the possible reaction of economic agents, from individual companies to local and global markets and economies.

This study is devoted to modelling and assessing the impact of oil shocks on the Russian stock market.

\section{Methods}

The issue of studying complex dynamical systems has aroused great interest of many scholars as it is of an interdisciplinary nature. Much attention is given to energy saving and energy efficiency [1]. To study economic dynamics in practice, two approaches are usually used: stochastic dynamic general equilibrium models (DSGE, SDGE) and a family of vector auto regression models (VAR models). The latter are especially popular, since they are based on objective data (statistical time series describing real economic phenomena) and allow modeling the impulse response to a certain type of external macroeconomic shock, as well as assessing its contribution to the dynamics of changes in some endogenous variables. VAR models can be used to solve forecasting problems [2].

In the classical form, the VAR model consists of $K$ endogenous variables $y_{t}=\left(y_{l t}, \ldots, y_{k t}, \ldots, y_{K t}\right)$, where $k=1, \ldots, K$. VAR(p) process can be expressed as follows:

$$
y_{t}=A_{1} y_{t-1}+\ldots+A_{p} y_{t-p}+u_{t}
$$

where, $A_{\tau}$ coefficient matrix of dimension $(K \times K)$,

$u_{t}-\mathrm{K}$-dimensional random process of "white noise" type with mathematical expectation equal to 0 .

If additional assumption is accepted that the process $u_{t}$ has a normal distribution law, then model (1) is a Gaussian vector auto regression model.

Matrix $A_{0}$ with dimensions $K \times 1$ consists of free expressions for individual equations, and the matrix $\left\{A_{p}: p=1,2, \ldots P\right\}$ with dimensions $(K \times K)$ describes the impact of $p$ lag of $y_{t}$ variable on its current value.

The most important property of VAR model is stationarity, which can be interpreted as attenuation of the impact of $u_{t}$ shock on the values of the vector of $y_{t}$ variables. This property 
should be validated when developing the model specification using appropriate statistical tests.

Detailed description of the essence and properties of models of the VAR family can be found in the literature [2, 3, 4]. The famous scientist Christopher Sims, Nobel Prize winner in economics [4], introduced VAR model. At present, several modifications of this model (SVAR, BVAR, etc.) have been developed which make it possible to eliminate a number of shortcomings of the classical representation and to solve more complex problems.

VAR model and its various modifications are widely used in scientific research, and. in particular, in those related to the analysis of the impact of oil shocks on key macroeconomic indicators. For example, the work [5] is devoted to study of the relationship between shocks in foreign exchange markets and monetary policy in the United States. It analyzes the impact of oil shocks on monetary policy in the United States [5]. Assessment of the impact of fluctuations in oil prices on a number of emerging markets is presented in the work [6].

Among modern studies of Russian scientists using VAR models, the works [7, 8, 9] should be highlighted. The work [3] is devoted to study of the impact of oil shocks on Russian GDP. The influence of oil prices on the domestic financial market was considered in [10]. However, the results of the research mentioned above are controversial and seem to be outdated.

This study attempts to analyze the impact of the oil shock on the Russian stock market and its possible consequences at the present stage. The study is divided into two interrelated sections. The first section presents the results of processing the initial data, calculating their key characteristics and preliminary analysis. The second section of the study is devoted to modeling the assessment of the impact of oil shocks on the behavior of RTS stock index.

The information base of the study was the time series of daily prices for Brent oil and the values of RTS stock index for the period from 1997 to April 30, 2020 (the total of 6088 observations). The choice of RTS index is due to the fact that its values are calculated in US dollars. The data source was Bloomberg global information system. Initial data processing and modeling of the impact of shocks on the index value was carried out in the free software environment R [11].

\section{Results and discussion}

One of the aims of the study is analyzing the dynamics of time series and determining their statistical characteristics. It presents certain interest to analyze the dynamics and relationship of oil prices and RTS stock index. The results of the graphical analysis of the initial data are shown in Fig. 1 and Fig.2. It is obvious that visually both rows demonstrate similar behavior. The charts clearly show almost synchronous drops in the price of Brent oil and the values of RTS index (for example, the Russian crisis in 1998, the global financial crisis in 2008 and the beginning of the economic recession in 2020).

Results of calculating the statistical characteristics of studied series are given in Table 2.

Table 2. Statistical characteristics of Brent and RTS series for 1997 - April 2020

\begin{tabular}{|c|c|c|}
\hline Indicator & Brent oil (USD) & RTS (units) \\
\hline Mean & 58.52 & 971.77 \\
\hline Std. Dev & 32.22 & 585.80 \\
\hline Min & 9.64 & 38.53 \\
\hline Q1 & 28.45 & 396.15 \\
\hline Median & 56.40 & 1014.40 \\
\hline Q3 & 77.75 & 1413.80 \\
\hline Max & 146.08 & 2487.92 \\
\hline MAD & & \multicolumn{2}{c|}{686.03} \\
\hline
\end{tabular}




\begin{tabular}{|c|r|r|}
\hline IQR & 49.29 & 1017.57 \\
\hline Skewness & 0.42 & 0.17 \\
\hline Kurtosis & -0.88 & -0.92 \\
\hline
\end{tabular}

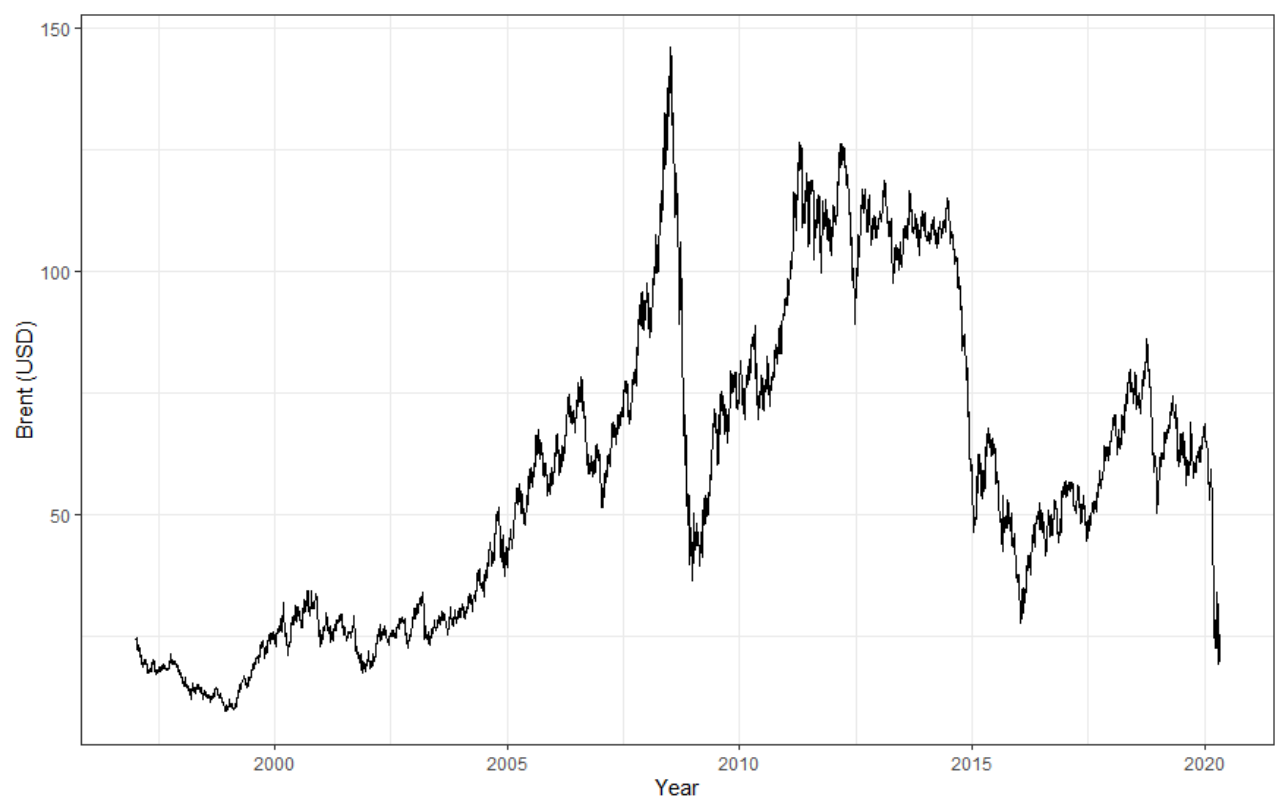

Fig. 1. Dynamics of Brent Crude Oil Prices for 1997 -April 2020

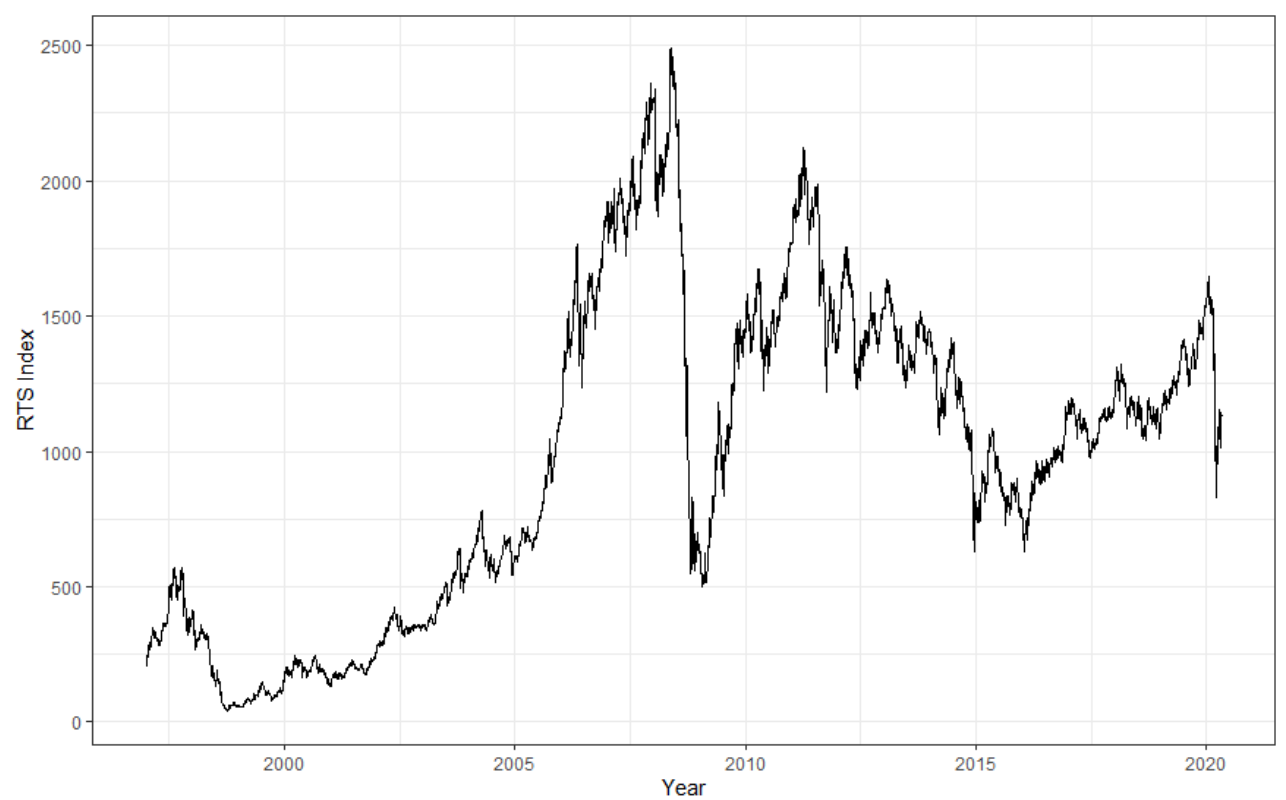

Fig. 2. Dynamics of RTS Index Values for 1997 - April 2020

The results obtained allow to conclude that the probability distribution of both series is not normal. This, in particular, is marked by the indicators of asymmetry (Skewness) and elongation (Kurtosis). Significant volatility of both variables is also noted. 
For further analysis, the logarithmic changes (profitability) of Brent oil and RTS index were determined and brought to monthly periods. A graphical analysis of the results obtained is shown in Fig. 3.

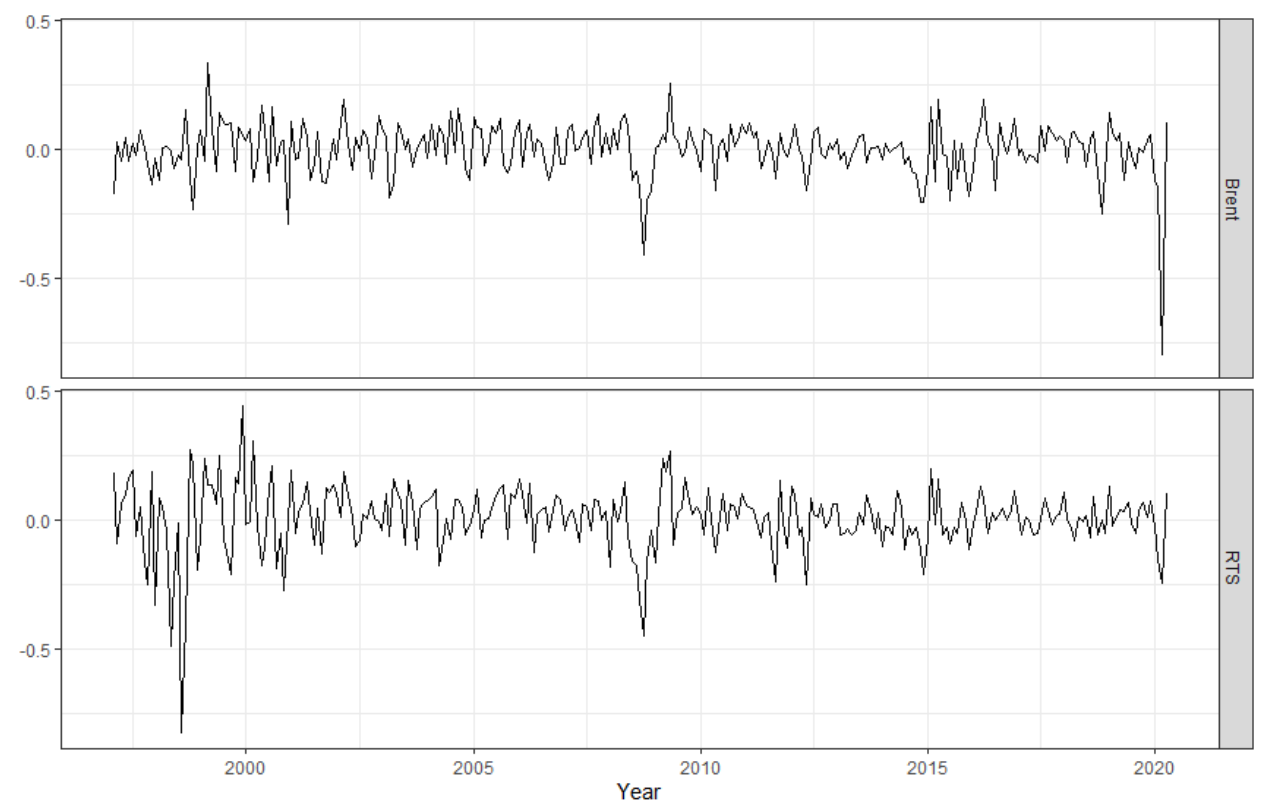

Fig. 3. Dynamics of changes in the profitability of Brent oil and RTS Index

The calculation of the statistical characteristics of obtained series is given in Table 3. For greater clarity, the results of correlation analysis and analysis of probability distributions are presented in a graphical form (Fig. 4).

Table 3. Statistical characteristics of Brent and RTS series for 1997 - April 2020

\begin{tabular}{|c|r|r|}
\hline Indicator & Brent oil (USD) & RTS (units) \\
\hline Mean & 58.52 & 971.77 \\
\hline Std. Dev & 32.22 & 585.80 \\
\hline Min & 9.64 & 38.53 \\
\hline Q1 & 28.45 & 396.15 \\
\hline Median & 56.40 & 1014.40 \\
\hline Q3 & 77.75 & 1413.80 \\
\hline Max & 146.08 & 2487.92 \\
\hline MAD & 39.57 & 686.03 \\
\hline IQR & 49.29 & 1017.57 \\
\hline Skewness & 0.42 & 0.17 \\
\hline Kurtosis & -0.88 & -0.92 \\
\hline
\end{tabular}

As follows from Table 4, the series under study have similar values of means, medians, and standard deviations, but they differ significantly in the coefficients of maximum change in yield, asymmetry and kurtosis.

Both distributions in Fig. 4 are sloped to the left, while the distribution of RTS returns is slightly sharper. Particularly noteworthy is the low correlation coefficient $(0.307)$ between changes in yields, which contradicts study results presented in [12]. 
Table4. Statistical characteristics of Brent and RTS yield series for 1998 - April 2020

\begin{tabular}{|c|c|c|}
\hline Indicator & Brent daily yield & RTS daily yield \\
\hline Mean & 0.01 & 0.01 \\
\hline Std. Dev & 0.10 & 0.12 \\
\hline Min & -0.55 & -0.56 \\
\hline Q1 & -0.05 & -0.05 \\
\hline Median & 0.01 & 0.01 \\
\hline Q3 & 0.07 & 0.08 \\
\hline Max & 0.40 & 0.56 \\
\hline MAD & 0.09 & 0.10 \\
\hline IQR & 0.12 & 0.13 \\
\hline Skewness & -0.62 & -0.22 \\
\hline Kurtosis & 4.16 & 3.20 \\
\hline
\end{tabular}
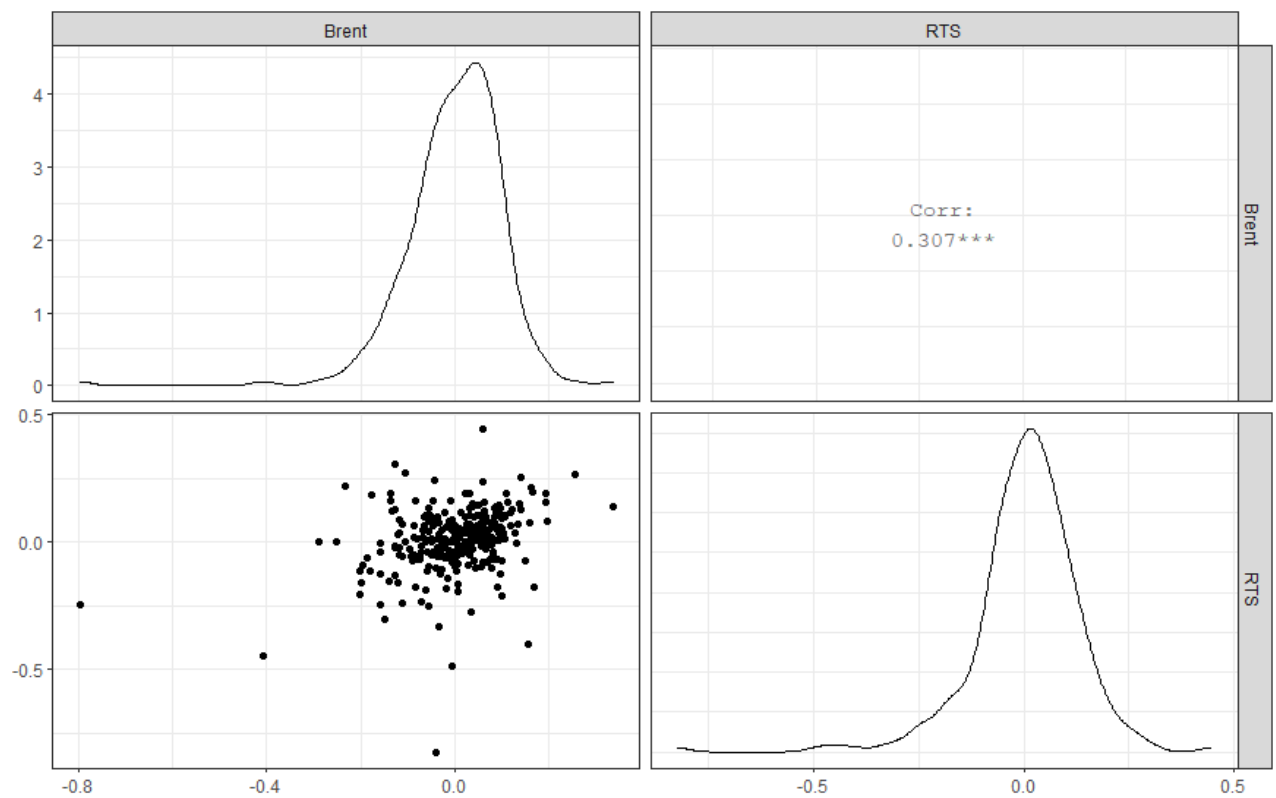

Fig. 4. Probability distribution and correlation of returns on Brent oil and RTS stock index

Formulation of VAR model requires preliminary testing of initial data for stationarity. The essence and methods of such testing are described in detail in the literature. Table 4 below shows the results of studying the stationarity of the model using extended DickeyFuller test).

Table 5. Results of series analysis for stationarity

\begin{tabular}{|c|c|c|}
\hline Indicator/characteristic & Brent & RTS \\
\hline Dickey-Fuller (DF) & -6.5156 & -5.9556 \\
\hline Lag & 6 & 6 \\
\hline p-value & $<0.01$ & $<0.01$ \\
\hline
\end{tabular}


As follows from Table 5, obtained series are stationary (p-values less than 0.05 ) at the 95\% confidence level according to DF test.

The second stage of study is devoted to solving the following problems: 1) specification and testing of VAR model; 2) application of obtained model to assess the impact of oil shocks; 3 ) forecasting. Special attention is given to modeling of oil shocks impact on RTS Stock Index.

One of the most important tasks in the development of VAR model is selection of an adequate time lag. Currently, several approaches have been developed to solve it, the consideration of which is beyond the scope of this article. It should be noted that modern econometric methods and information technologies offer researchers developed toolkit for solving this problem [3].

The choice of the time lag was carried out based on the use of the most famous statistical information tests AIC (Akaike test), BIC (Schwartz test), and HQIC (Hennan and Quinn test). The results of carried out analysis showed the expediency of choosing a model with a delay in two periods, i.e. VAR models (2).

A fragment of the VAR model (2) implementation results for the series under study in the environment R is shown in Fig. 5 (for shortening purposes, the result is shown only for RTS).

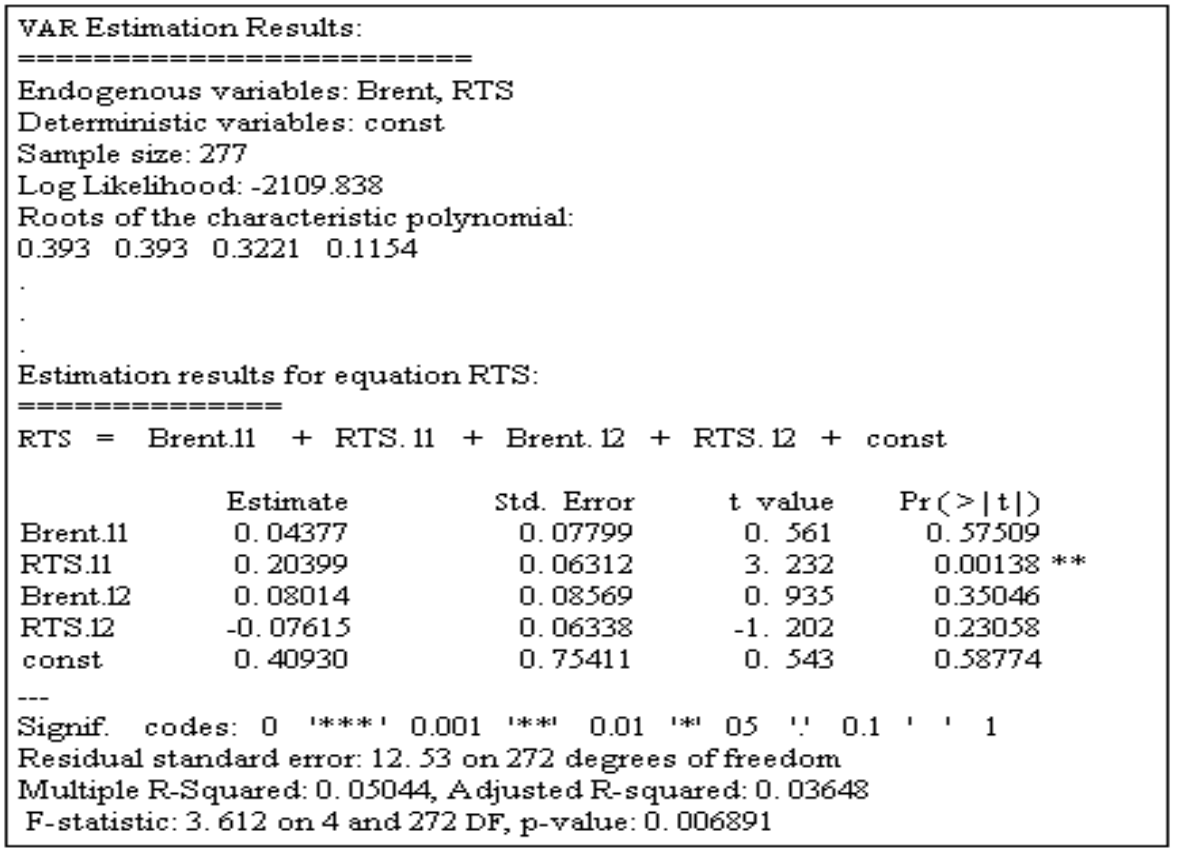

Fig. 5. Fragment of the VAR model (2) application to the initial data

The given printout shows the value of all roots (Roots line of the ...) less than one, which indicates that the resulting model is stationary. It also follows from the results that the RTS value profitability significantly depends on its own delays in 1 period (RTS.11 indicator on the printout). Thus, it is more inertial than a number of changes in Brent oil.

The stationarity of VAR model allows it to be reduced to an endless process of the vector moving average (VMA):

$$
y_{t}=\mu+\sum_{k=0}^{\infty} \theta_{k} \times \varepsilon_{t-k},
$$


where, $\theta$ - matrix with dimensions $(K \times K)$ reflecting the reaction of successive changes in endogenous variables generating the vector $y_{t}$ to the random component $\varepsilon$ during $k$ - periods. Accordingly, this matrix is given by the following equation:

$$
\theta_{k}=\frac{\partial y_{t+k}}{\partial \varepsilon_{t}}
$$

In order to determine the values of matrix $\Theta$, as well as to check the stationarity of obtained VAR model (2), we will carry out its reduction to VMA process. The values of matrix $\Theta$ obtained as results of a hundredfold generation of VMA process for the first 4 and last 100th periods are presented in Table 6.

Table 6. Value of $\Theta$ matrix

\begin{tabular}{|l|l|l|l|l|l|l|}
\hline Variable & \multicolumn{1}{|c|}{$\boldsymbol{\Theta}_{\mathbf{0}}$} & \multicolumn{1}{|c|}{$\boldsymbol{\Theta}_{\mathbf{1}}$} & \multicolumn{1}{|c|}{$\boldsymbol{\Theta}_{\mathbf{2}}$} & \multicolumn{1}{|c|}{$\boldsymbol{\Theta}_{\mathbf{3}}$} & \multicolumn{1}{c|}{$\boldsymbol{\Theta}_{\mathbf{4}}$} & \multicolumn{1}{c|}{$\boldsymbol{\Theta}_{\mathbf{1 0 0}}$} \\
\hline Brent & 1.00 & 0.063 & -0.037 & 0.012 & 0.015 & 0.00 \\
& 0.00 & 0.13 & 0.15 & 0.023 & -0.0094 & 0.00 \\
\hline RTS & 0.00 & 0.044 & 0.092 & 0.019 & -0.0056 & 0.00 \\
& 1.00 & 0.20 & -0.029 & -0.004 & 0.0143 & 0.00 \\
\hline
\end{tabular}

As it has been noted, the most important interpretation of $\Theta$ matrix values is the reflection of the effect of a random shock on the variables under study. For example, in our case, the values of the matrix $\Theta 1$ are interpreted as follows: upon the occurrence of the first random shock $\varepsilon 1 \mathrm{t}=1$, the value of RTS index within the period $\mathrm{t}+1$ will be higher by 0.044 ; the second shock - by 0.2 , etc.

The instantaneous response to shock in period 0 is represented by the unit matrix. In addition, graphical analysis of the matrix values shows that the effect of shocks after about 25-30 periods fades away and tends to 0 . Thus, there is one more confirmation in favour of the stationarity of the model.

Testing of constructed VAR model (2) for autocorrelation of residuals was carried out using the Ljung-Box and Breush-Godfrey methods. The test results are shown in Table 6.

Table 7. Results of testing the model for autocorrelation of residuals

\begin{tabular}{|c|c|c|c|c|c|c|c|}
\hline \multicolumn{4}{|c|}{ Ljung-Box method } & \multicolumn{4}{c|}{ Breush-Godfrey method } \\
\hline sequence & LB statistics & DF & p-value & sequence & BG statistics & DF & p-value \\
\hline $\mathrm{h}=3$ & 3.61 & 4 & 0.461 & 1 & 4,26 & 4 & 0,372 \\
\hline $\mathrm{h}=4$ & 7.17 & 8 & 0.518 & 2 & 8,81 & 8 & 0,359 \\
\hline $\mathrm{h}=5$ & 9.46 & 12 & 0.664 & 3 & 11,33 & 12 & 0,501 \\
\hline $\mathrm{h}=6$ & 17.00 & 16 & 0.385 & 4 & 16,60 & 16 & 0,412 \\
\hline
\end{tabular}

The results obtained show the absence of serial autocorrelations in the residuals ( $p$-value $>0.05$ ). The model was tested for normality of the distribution of residuals using the DornikHansen method, and the hypothesis of normality was confirmed.

The final test for stability of the model was carried out using the CUMSUM method. In order to save space, its results are shown graphically (Fig. 6). 

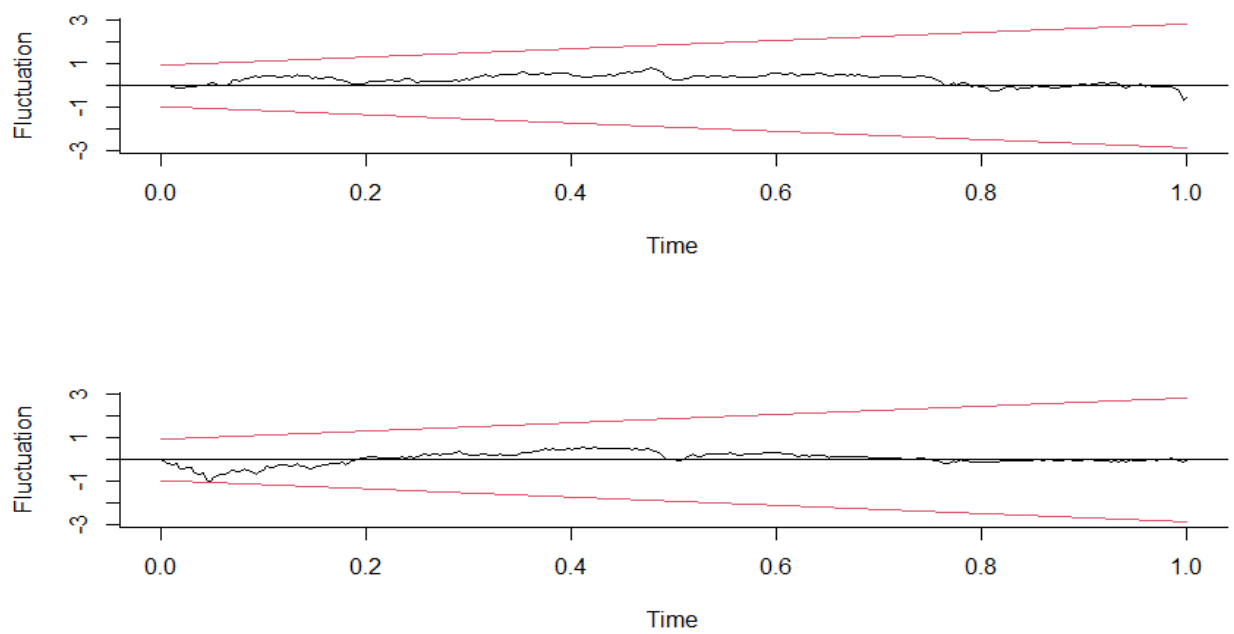

Fig. 6. CUMSUM test results (upper Brent chart, lower - RTS)

The conclusion obtained from the graphical analysis testifies in favour of the stability of constructed VAR model (2).

The resulting model can be used to assess the impact of oil shocks on the return on RTS index, as well as to forecast its values. form:

The impact can be assessed using a so-called impulse-response function (IRF) of the

where $\varphi_{j}-$ set of shocks.

$$
\begin{array}{ll}
I R F_{k(i .} & \partial v_{i+\perp v} \\
\text { Time }
\end{array}
$$

Fig. 7 shows the response of studied variables to an external single shock. Dotted lines indicate the $95 \%$ confidence interval.

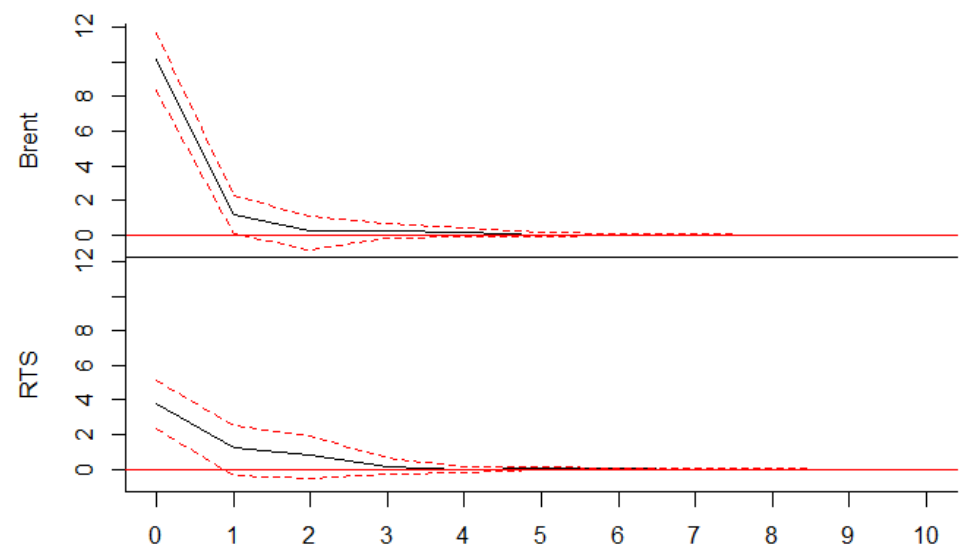

$95 \%$ Bootstrap $\mathrm{Cl}, 100$ runs

Fig. 7. Response of studied variables to a single shock 
The main interest in our study is the possible reaction of the index to sharp changes in oil prices.

Let us define the shock value as $30 \%$ decline in the price of Brent oil (or 3 standard deviations, ref. to Table 3). It should be noted that we are interested in the decline, since the rise in prices generally favors the growth of Russian stock indices. The results of modeling a similar situation are presented in Table 7.

Table 8. Reaction of RTS index to $30 \%$ decline in Brent oil prices

\begin{tabular}{|l|c|c|c|c|c|c|c|c|c|c|}
\hline Period & 1 & 2 & 3 & 4 & 5 & 6 & 7 & 8 & 9 & 10 \\
\hline$\Delta$ RTS,$\%$ & $-11,37$ & $-3,79$ & $-2,46$ & $-0,52$ & 0,07 & $-0,03$ & $-0,03$ & 0,00 & 0,00 & 0,00 \\
\hline
\end{tabular}

As follows from the obtained results, a sharp drop in prices $(30 \%)$ will lead to a one-time decline in the stock market (RTS index) by about $11.4 \%$. It should be mentioned that this reaction is generally consistent with the behavior of Brazilian IBOVESPA index (Table 1). At the same time, the consequences of the oil shock will last about 6 months, after which the process will stabilize.

VAR models allow forecasting for the required number of periods with a given confidence interval. It should be noted that such forecasts are derived exclusively from the past dynamics of the variables used and do not take into account the influence of other factors. In this regard, the forecasting of monthly values of RTS index for the next 12 months (i.e. from May 2020) based on obtained model is carried out below to demonstrate the capabilities of applied approach. A graphic illustration of the results obtained is shown in Fig. 9.

\section{Brent}

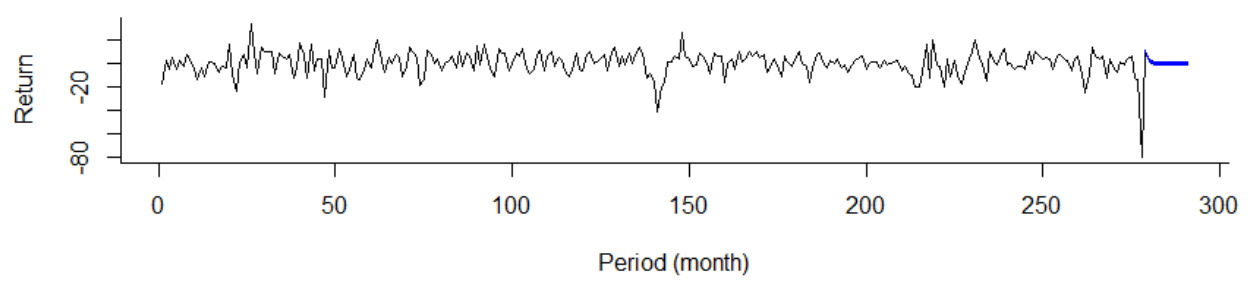

RTS

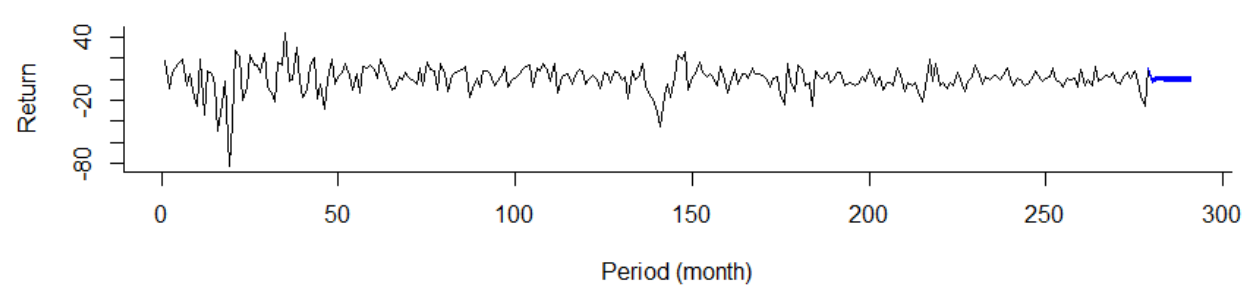

Fig. 9. Forecast of changes (profitability) of RTS index for the next 12 months

It is assumed that within two months the RTS index will win back the losses incurred, after which the mean \pm standard deviation will return to the "historical" corridor (Table 3 ).

It should be noted that such scenarios (the so-called V-shaped recovery of both the market and the economy as a whole) are put forward by a number of expert economists and are popular among a certain part of market participants. Without getting involved in polemics on 
this issue, we note that in the "data-generated" world, the probability of the implementation of econometric forecasts can be quite high.

In our opinion, such forecasts are more useful for understanding possible development trends in the real world and, of course, should not be taken as a guide to action.

The approach and mathematical tools considered in this study can be used to solve a wide range of practical tasks. In our opinion, it is of particular interest for the Russian economy, which is really subject to shocks of various origins (socio-political, financial, legislative, environmental, etc.), the consequences of which should be assessed at all levels of management.

Currently, there are many modifications of basic VAR model, which are specially adapted for solving a great number of problems. Advanced software tools (R, Python environments, SPSS, cloud information and analytical environments Microsoft Azure, IBM, Google, etc.) make it possible to automate computational procedures, data processing and simplify modeling.

However, the quality and applied value of mathematical models and the conclusions obtained as a result of their application still significantly depend on the initial data, the time periods selected for the study, the correctness of formulated hypotheses and given prerequisites. For example, the results obtained in the course of this study significantly differ from similar studies of other authors.

It was found that the variance of changes in Brent oil prices explains only about $10 \%$ of the variance in the return on RTS index over long time intervals. The low correlation of the series should also be noted. It is possible that the use of American oil WTI or Russian oil Urals as a benchmark for oil prices (data on its prices are not publicly available) would give different results.

It should be noted that RTS index currently includes no less than 40 shares and is only a kind of "surrogate" for domestic stock market, where more than 270 shares of Russian companies are traded.

Finally, it can be mentioned that the stock market is influenced by other factors that have not been considered in this study.

Despite the controversial issues mentioned above, there is no doubt that with the development of information storage and processing systems, econometric methods and models will play an increasing role in research.

\section{References}

1. Chikileva, L.S., Gorokhova, S.S., Popova, A.V. (2018). Main directions of Russian state energy saving policy in the field of electric power engineering. Light \& Engineering, 26 (4), 85-92.

2. Nosko, V.A. (2011). Econometrics. Book 2. Parts 3, 4.

3. Lütkepohl, H. (2013). Identifying Structural Vector Autoregressions Via Changes in Volatility. In T. B. Fomby, L. Kilian, A. Murphy (Eds.). VAR Models in Macroeconomics - New Developments and Applications: Essays in Honor of Christopher A. Sims. Advances in Econometrics, 32. Emerald Group Publishing Limited. 169-203.

4. Sims, CH. (1980). Macroeconomics and reality. Econometrica, 48. 1-48.

5. Hamilton, J. D., Herrera, A. M. (2004). Oil shocks and aggregate macroeconomic behavior: the role of monetary policy. Journal of Money, Credit \& Banking, 36(2), 265286. 
6. Aloui, C., Nguyen, D., Khuong, Njeh H. (2012). Assessing the Impacts of Oil Price Fluctuations on Stock Returns in Emerging Markets. Economic Modeling, 29, 26862695.

7. Votinov, A.I., Stankevich, I.P. (2017). VAR-approach to assessing the effectiveness of measures of fiscal stimulation of the economy. Financial Journal, 6, 64-74.

8. Shepeleva, M.A. (2020). Empirical analysis of the balance channel of monetary transmission for Russia. Financial Journal, 12(2), 39-56.

9. Fokin, N.D. (2019). VAR-LASSO-Model on a Large Volume of Russian Economic Data. Economic Development of Russia, 26(1), 20.

10. Polbin, A. (2016). On the dynamic relationship of the RF GDP and oil prices in the VARmodel. Problems of theory and practice of management, 7, 85-90.

11. The Comprehensive R Archive Network. Retrieved from: https://cran.r-project.org/

12. Fedorova,E.A., Lazarev, M.P. (2014). Influence of oil prices on the financial market of Russia during the crisis period. Finance and Credit, 20, 20-22. 